Nordic Concrete Research - Publ. No. NCR 61 - ISSUE 2 / 2019 - Article 7, pp. 107-129

\begin{tabular}{|c|c|}
\hline$S$ sciendo & 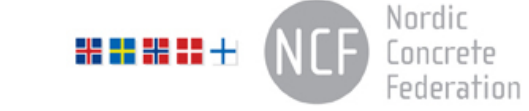 \\
\hline $\begin{array}{l}\text { (C) Article authors. This is an open access article distributed under } \\
\text { the Creative Commons Attribution-NonCommercial-NoDerivs } \\
\text { licens. (http://creaticecommons.org/licenses/by.nc-nd/3.0/). }\end{array}$ & $\begin{array}{l}\text { ISSN online } 2545-2819 \\
\text { ISSN print } \quad 0800-6377\end{array}$ \\
\hline DOI: $10.2478 /$ ncr-2019-0019 & $\begin{array}{r}\text { Received: Oct. 7, } 2019 \\
\text { Revision received: Dec. 18, } 2019 \\
\text { Accepted: Dec. 19, } 2019\end{array}$ \\
\hline
\end{tabular}

\title{
Bonded Concrete Overlays: A Brief Discussion on Restrained Shrinkage Deformations and Their Prediction Models
}

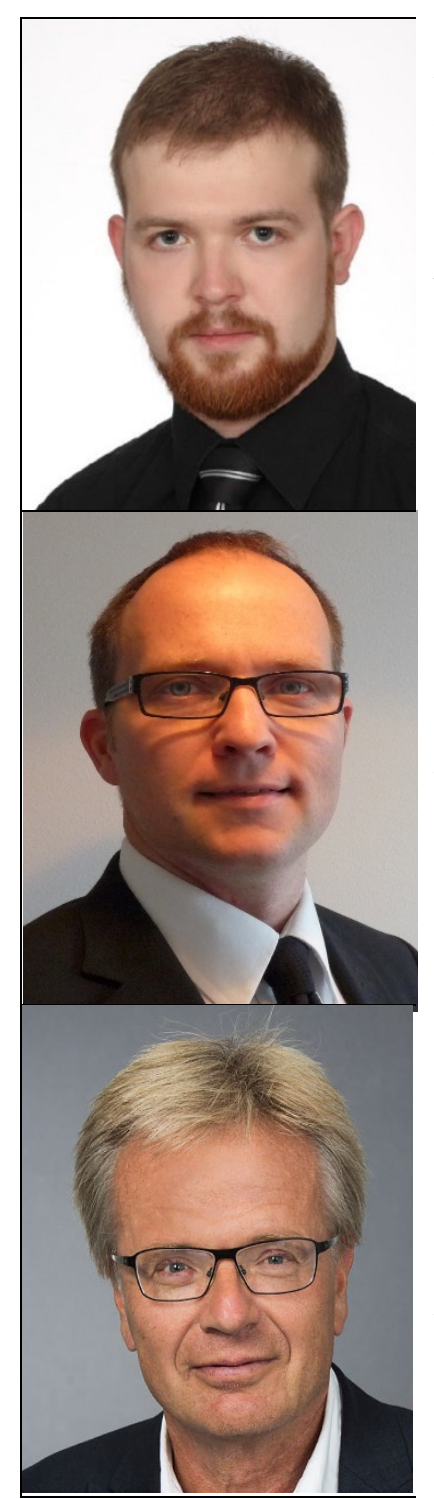

Wojciech Cyron, MSc

Ph.D. Student, Luleå University of Technology

Division of Building Materials and Structural Engineering; 97187 Luleå, Sweden

wojciech.cyron@1tu.se

Martin Nilsson, Associate Professor

Head of the division; Luleå University of Technology

Division of Building Materials and Structural Engineering;

97187 Luleå, Sweden

martin.nilsson@1tu.se

Mats Emborg, Professor

Luleå University of Technology,

Division of Building Materials and Structural Engineering;

Head of R\&D department, BetongIndustri AB;

97187 Luleå, Sweden

mats.emborg@1tu.se; mats.emborg@Betongindustri.se 


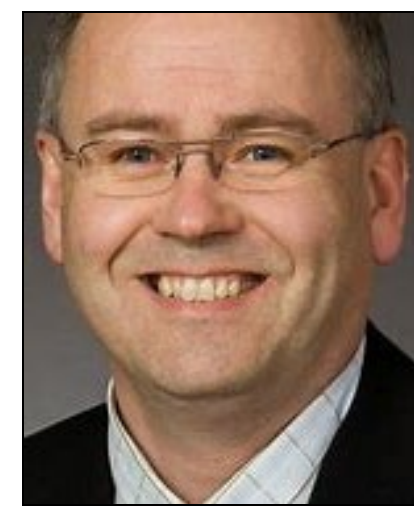

Ulf Ohlsson Ph.D.

Senior Lecturer, Luleå University of Technology

Division Building Materials and Structural Engineering;

97187 Luleå, Sweden

ulf.ohlsson@1tu.se

\begin{abstract}
Bonded concrete overlays (BCO) on bridge decks are beneficial solutions due to their superior properties as compared to the typical asphalt pavement. A significant number of overlays suffer however, from occurrence of cracks and delamination due to poor bond, and restrained shrinkage and thermal dilation. Over the past years different appraisals for estimation of the restrained deformations have been developed, from micro-scale models, based on poromechanics, to empirical equations as given in B3 or B4 models suggested by Bažant. This paper provides a short overview of calculation models along with a brief theoretical explanation of shrinkage mechanism.
\end{abstract}

Key words: bridge, overlay, concrete, shrinkage, creep

1.

INTRODUCTION

1.1

Performance of bridge overlay

Two types of overlays on bridges are used in order to secure a comfortable driving and a structural behaviour of the bridge deck. Those technologies involve concrete overlays, which are cast directly onto the structural concrete, and overlays with a system of layers with bitumen topping as wearing coarse of a pavement, Figure 1. Past studies within The Swedish Universities of the Built Environment (SBU), , have shown economical superiority of concrete overlays, compared to the bitumen system, due to better wearing capacity and durability, but primarily due to a degradation of the isolating part of the bitumen system [1]. An increase of permeability is considered to be a result of air bubbles formation in the insulation. Although the nature of this process is not fully understood, it is assumed that discussed problem could be caused by heating of the layer during the placing.

By employing a concrete overlay cast directly onto the structural part, any other layer can be excluded, thus the only factor for possible deterioration is the lack of quality of the concrete overlay performance. Such solution is usually denoted as bonded concrete overlay (BCO). In the past, problems and drawbacks have been identified within this solution, such as cracking and delamination of the overlays with hindered deformations as the driving factor. Despite vast scientific contribution in the subject, problem has been only partially solved by introducing suitable amount of reinforcement. Still, several novel reports regarding condition of concrete overlays inform about presence of flaws [1]. 


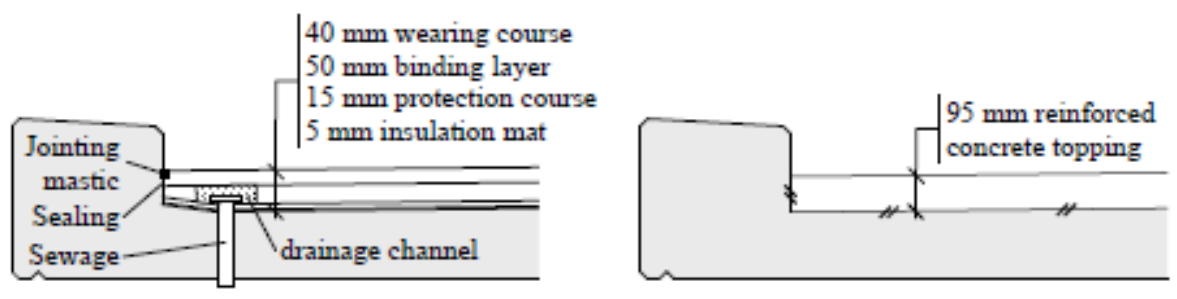

Figure 1- Two types of overlays: Bitumus (on left) and bonded concrete (on right). Modified from [93].

It has been reported in 2011 that about 550 bridges in Sweden were covered with bonded concrete overlays [2]. Within ongoing doctoral studies at LTU, all bridges administrated by the Swedish Transport Administration (TRV) in the northern part of Sweden (NORD, which comprises administrative regions of Norrbotten, Lappland and Västerbotten) have been compiled with use of the Bro och Tunnel Management Database (BaTMan) [92]. Thus, in 2011 in the NORD region, 170 overlays have been reported as executed with BCO, while in 2018 this number raised to 265 (of 2255 bridge objects in total reported in NORD region). Although the number of objects with $\mathrm{BCO}$ rapidly increased, almost every fifth concrete overlay inspected by TRV and reported in the database were to some extent damaged.

In order to define more quantitatively present flaws in concrete overlays and to recognize main factors behind the flaws, information reported during TRV inspections has been collected, evaluated and presented, see Figure 2. Photos (crack pattern and distribution for instance) and given measurements were used as a base in the process of validating the results that were made during the inspection. On one hand, it can be observed that some of the presented flaws are more likely caused by poor execution than insufficient preparation at the design stage. On the other hand, more than $12 \%$ of all BCOs are categorized as damaged by shrinkage (as about $60 \%$ of damages are due to shrinkage of concrete). It is noted that information from the database should be treated rather as an indication of the problem's scale, but not as a strict number. Moreover, one has to remember that the large objects owned by municipalities are not comprised within the database and also a significant number of industrial floors is touched by the discussed problem.

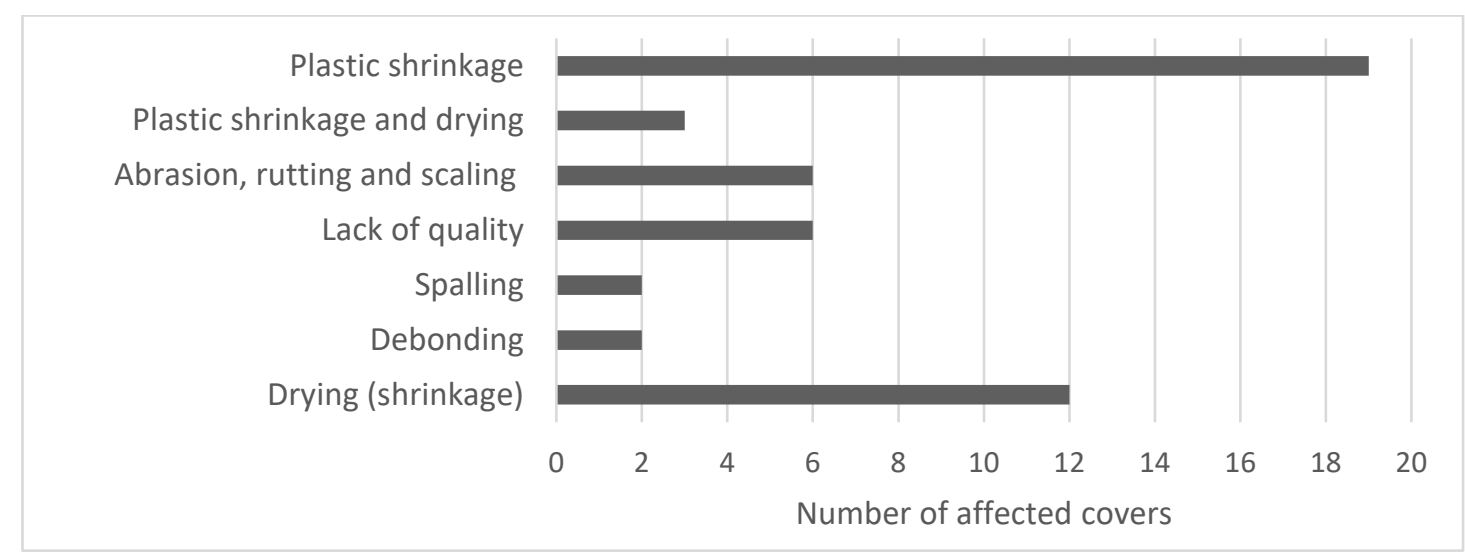

Figure 2 - Types of present flaws for bridges in NORD region based on documentation from BaTMan database [92]. 


\section{Restrained shrinkage cracking}

The majority of flaws is made up by cracks, which could further be divided into two main groups: shallow and thin cracks caused by desiccation (drying) shortly after casting in the plastic stage (plastic shrinkage), and larger cracks, which are caused by removal of water from the pore system during hardening (both self-desiccation and drying). The problem of plastic shrinkage has been studied exhaustively by e.g. Sayahi within parallel studies at LTU [3] and others, and thus the following text focuses on the deformations during hardening and in the hardened concrete. The second group of cracks usually affects the whole cross section and their width is typically not larger than $0.5 \mathrm{~mm}$, but still exceeds tolerable widths for many types of structures.

It is well known, that at full restraint and without any relaxation of the concrete, shrinkage of concrete due to the drying most often results in cracking, even if its free deformation is relatively small- several basis points. On one hand, the performance of concrete overlay could be secured by addition of suitable amount of fibres that distributes the cracks, as it was discussed for instance by Emborg and Carlswärd [4]. A negative feature of this solution is deterioration of the overlay conditions and aesthetical aspects by i.e. rusting of fibres that are sticking out of surfaces. On the other hand, several overlays have been performed within the cold and rainy autumn period without any reinforcement. Somewhat surprisingly, those overlays did not suffer from occurrence of any flaws for several years, see Figure 3, which leads to the conclusion that suitable ambient conditions (or good curing practice) can secure optimal performance of a concrete overlay as a result of slow shrinkage.

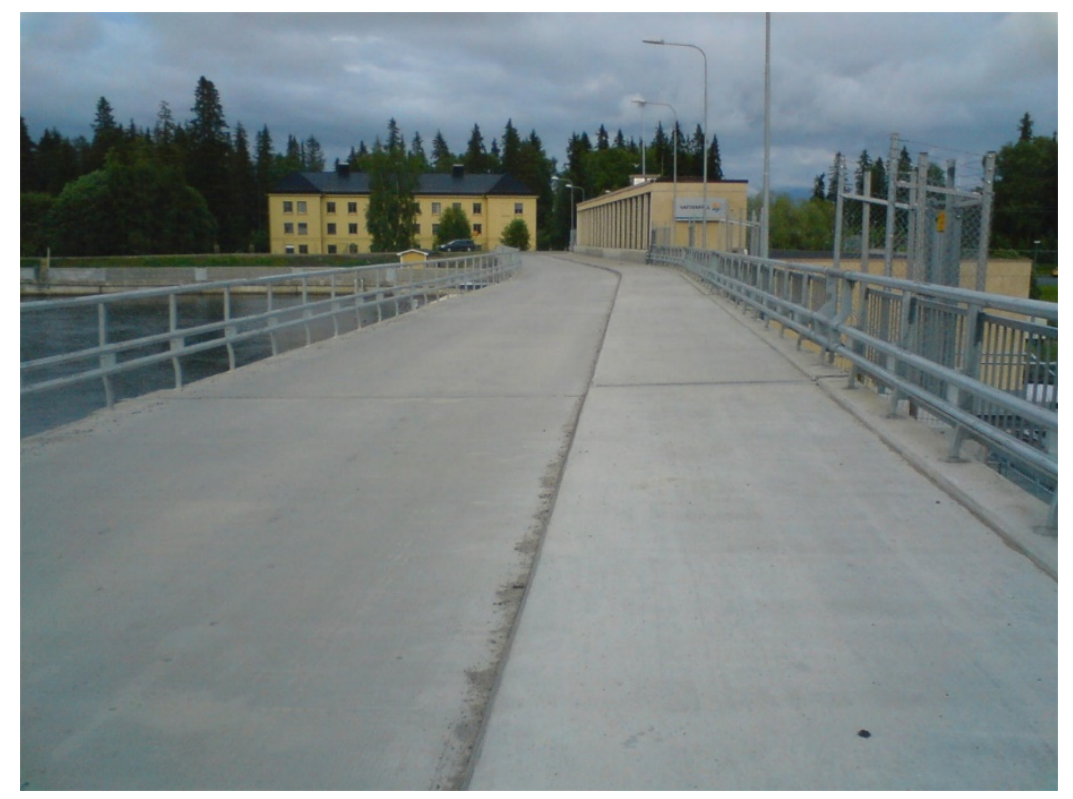

Figure 3 - Non-cracked pavement performed in 2010 in Bodforsens hydro power plant, Boden Un-reinforced and steel fibre reinforced areas in full scale tests. (photo by J. Carlswärd).

\section{3}

\section{Bond and preparation techniques}

It is important to observe that the bond is of crucial importance in the general performance of $\mathrm{BCO}$, as it determines composite action between old and young concrete, but it also affects the possible distribution of cracks in the overlay and occurrences of shear stresses [5]. The bond is 
usually understood as the tensile strength, that expresses general cohesive and adhesive force; and which is evaluated typically with the pull-off test. For the sake of simplicity, it is usually assumed that the tensile stresses appear in the overlay, while compressive are present in the substrate and no shear stresses at interface can appear. Birkeland discussed this approach, involving also the behaviour of the overlay close to the ends of the beam [6]. Later, numerical studies [5], confirmed that the horizontal, normal stresses present in the overlay change into both shear stresses and normal stresses, perpendicular to the plane of interphase. This phenomenon occurs only at the ends of the overlay or in close vicinity of the cracks, at a distance approximately three times larger than the thickness of the overlay.

As the most influential factors on bond, cleanliness, lack of microcracks, lack of laitance, compaction, curing and surface properties in the interphase plane have been given in literature. It has to be noticed that therefore, the largest contribution to the future bond has applied surface preparation technique $[7,8,9]$. The choice of preparation method has a tremendous impact on the properties of future bond. Evaluating experiments were performed by Silfwerbrand and Courard $[7,10]$ just to mention few, who gave an explanation of preparation procedures in a) increase of bonding effective area and in interlocking (positive) and b) in microcracking of substrate's superficial part (negative). In fact, the direct effect of roughening was not fully clear, and on one hand could be considered as a minor effect $[7,11]$. On the other hand, roughening cannot explain discrepancies with similar surface properties but different adhesive strength and vice versa [7,10]. For example: A wire-brushed surface has slightly higher effective area than a polished one, yet the difference in tensile stresses during the pull-of test can be significant. Confirmation of the previous observation was also presented by Sadowski, who also took an exposed aggregate surface into consideration, suggesting that exposure of aggregate is more important than the increase of bonded area [12]. Although such statement is supported by an increase in adhesion after polishing of surfaces, it cannot quantitatively involve the effect of laitance removal.

Another investigation of the interphase structure was undertaken by Beushausen who evaluated the effect of pre-moistening on the forming ITZ (interface transition zone) [13]. The idea of covering old concrete with water to saturated surface-dry (SSD) state is well known, and has been discussed widely by e.g. Morgan [14]. Furthermore, it is indicated in [14] that a hand after touching a moistened concrete surface, should remain dry. The reason for such action is to reduce the shrinkage strain development, which, in case of a dry substrate, will be accelerated due to overlays desiccation by suction form substrate. One has to consider if any pre-moistening can be performed (support made of dense high performance concrete), or if it is desirable (large selfdesiccation). Results of Beushausen [13] revealed intriguing tendencies, as oven dried specimens provided the best bond due to the less porous structure. However, this is of two-folded nature because the lack of pre-wetting likely affects internal and interfacial stresses.

One has to take into consideration the effect of casting technique and method of compaction, as they are not without an influence. It is well known, that bond can be tremendously affected by the workability of fresh concrete. The reason for such is that during casting, part of voids created during roughening starts to entrap air, lowering the bond strength. Some reports recommend to use vibration pokers or beams for the removal of entrapped air, however use of self-compacting concrete could also increase the bond between to concretes [15]. Although large scientific input exists regarding establishing of bond between self-compacting concrete, SCC, and reinforcement, there are very limited explanations on how the workability of SCC impacts on the bond between old and new concrete. For instance, Carlswärd [15] suggested a positive effect of high workability on bond in the case of roughened surface, however, no precise results were given. 


\section{$1.4 \quad$ Need for research}

An accurate prediction of restrained deformations is quite difficult as the complexity of occurring processes in cement paste during hardening is tremendous. Concrete shrinkage still features controversies around its very nature, and even the most advanced approaches based on microscale material model behaviour seems not be able to depict the whole ongoing process fully. On the other hand, engineers must rely on some simplified solutions, yet at the same time being robust and reliable. The way to a successful design therefore should lie in suitable simplifications that would allow incorporating the main factors such as fluctuations of external conditions (humidity and temperature), structural effects of size and so on. Therefore, it is worthy here to recall Bažant's statement [16], that even advanced finite element calculations make a little sense, if material is considered in inappropriate way.

The first aim of the research is thus to reconsider modern standard approaches for shrinkage calculations and it is concluded that it is almost impossible to discuss it without, at least, a brief review of the main mechanisms along with the creep. It also has to be considered that the perfect bond can secure good distribution of cracks on pavement delaying the deleterious effects in concrete pavements.

\section{THE MECHANISM OF SHRINKAGE}

In a traditional approach, shrinkage of concrete is usually divided into five types, which in reality occurs only in cement paste, yet in presence of restraining aggregates. Those five are traditionally coined as chemical, plastic, autogenous, drying and carbonation shrinkage, depending on the mechanism and age of occurrence [3]. For the sake of simplicity, one can assume that there are only two driving factors for the shrinkage: hydration and drying, Figure 4. While the desiccation leads to occurrence of capillary tension within the pore system, chemical changes may cause either contraction or expansion (for instance formation of magnesium hydroxide typical for expansive cements). It is also important to notice that drying per se does not induce carbonation, yet contact with environment and accessibility of $\mathrm{CO}_{2}$ is necessary for the reaction to proceed. Contribution of that factor onto the whole deformation is usually very small, and for structural analysis of the concrete overlay is of minor importance.

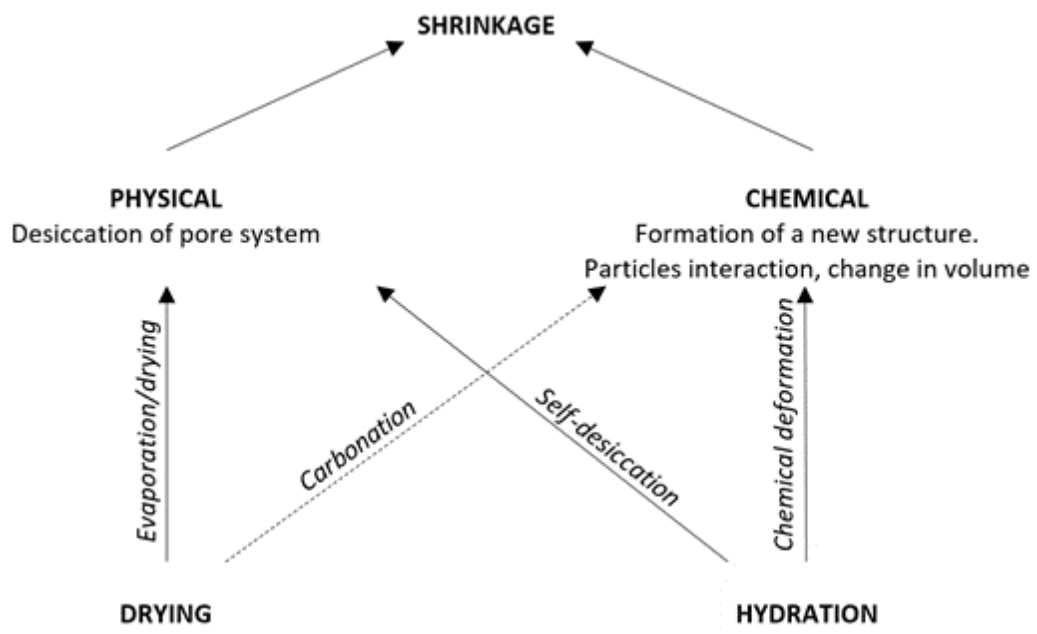

Figure 4 - Driving mechanisms of shrinkage. 
The model codes [36,37,63] suggest existence of autogenous and drying deformations independently, which is not always valid. One has to remember that the rates of both drying and hydration are governed by the moisture state in the pore system. Several experimental investigations into maturity concepts along with numerical simulations have been presented in the past years, clearly indicating the influence of drying onto the proceeding hydration. Therefore, since the environmental conditions affect hydration (and thus basic contraction), each different "path" of drying should also result in different strain situations in a concrete body. Hence, modelling process is a complex task and the challenge lies therefore in simplifying existing methodologies in the most robust engineering way.

\subsection{Chemical and basic contraction}

The hydration products are known to have a different volume than the substrates, which results in chemical deformation (usually contraction, however expansion can also be present [17]). This deformation is internal and about 6-7\% of the volume for ordinary Portland cement, but it may vary for different binder compositions [17]. Once the setting starts, rearrangement of hydrating particles is no longer possible and internal deformation starts to manifest as external (always lower than volumetric change). The external deformation due to this phenomenon is known as autogenous shrinkage. It is important here to recall the statement made by Tazawa [18] more than 20 years ago, saying that autogenous shrinkage occurs only after setting, without exchange of water and heat with the environment. Fulfilling the last requirement in laboratory is challenging, as perfect sealing in a long-term test is almost impossible and drying contributes to the measurement as well [19]. The setting time becomes also questionable in which desiccation is likely present as well [20], however, creep and relaxation at such age are tremendously pronounced and contribution of very early age self-desiccation is disputable.

The main mechanism behind autogenous shrinkage is usually considered as the deprivation of the pore system due to hydration. However, any uniform agreement regarding its very nature has not been achieved so far. Commonly, basic contraction is described as an elastic response of the pore system under action of changing capillary tension, which will be discussed below in text [21;22]. Long-term basic contraction could also be viscoelastic in its nature [23]. On the other hand, hydration is known to proceed for long time in sealed conditions, as self-desiccation is rather unable to cease the reaction, which could also result in a long-term shrinkage [24]. In a majority of cases (except humid environment and massive structures), drying and reaction itself ceases basic contraction within months, as proposed by Bažant [25]. Another idea was presented by Abuhaikal, who tried to explain this long-term deformation with a change in colloidal forces of $\mathrm{C}-\mathrm{S}-\mathrm{H}$ phase [26]. It is intriguing to observe, that each of those two mechanisms does not exclude another and further explanations of autogenous shrinkage nature are required.

\subsection{Microscale explanation of shrinkage}

For the simplicity of approach, one could state that total deformation is connected with the removal of evaporable water from the pore system. Despite given above, capillary tension is not the only mechanism governing shrinkage in the microscale level. Although suggestions were made when they become a driving mechanism, consensus has not been achieved [21;27]. A review of available theoretical explanations has been presented by e.g. $[21 ; 28]$. Therefore, some of them are only briefly discussed here. 
From a mathematical perspective, capillary tension theory is applicable for a relative humidity in the range between $40 \%$ and $100 \%$, and by that, it is usually considered to be sufficient meaning to explain the mechanism of shrinkage. Although discrepancies between theoretically determined and measured deformations can be observed for humidity range below $70 \%$, capillary tension theory can explain the key factors for a majority of natural conditions in a simple and robust way. The relation between humidity and pressure can be written as an equilibrium between YoungLaplace (1) and Kelvin's (2) equations for capillary pressure $P$, Figures 5 and 6 :

$$
\begin{aligned}
& P=-\frac{2 \gamma \cos \theta}{r^{\prime}} \\
& P=\rho \frac{\mathrm{R} T}{M} \ln \left(\frac{R H}{100}\right)
\end{aligned}
$$

where, $P$ - capillary pressure $[\mathrm{Pa}], r$-radius of menisci $[\mathrm{m}], r^{\prime}$ - radius of menisci at full wetting, $\mathrm{R}$ - gas constant $\left[\mathrm{J} /\left(\mathrm{mol}^{*} \mathrm{~K}\right)\right], \gamma$-surface tension $[\mathrm{N} / \mathrm{m}], \theta$-contact angle $\left[{ }^{\circ}\right], \rho$-density of liquid $\left[\mathrm{kg} / \mathrm{m}^{3}\right], T$-temperature $[\mathrm{K}], M$-molar mass $[\mathrm{kg} / \mathrm{mol}]$.

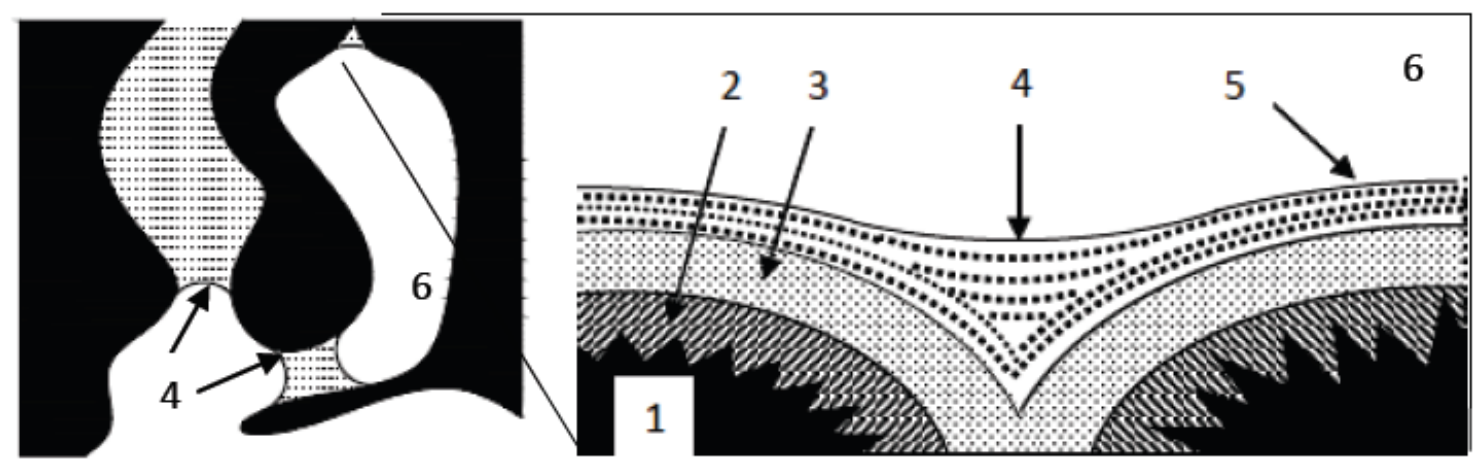

Figure 5 - Water in pore system; 1- unhydrated cement grain, 2-inner products (hindered adsorption region, 3- outer products (hindered adsorption region), 4-capillary menisci, 5- free adsorbed water, 6-Vapour. Modified from [30].

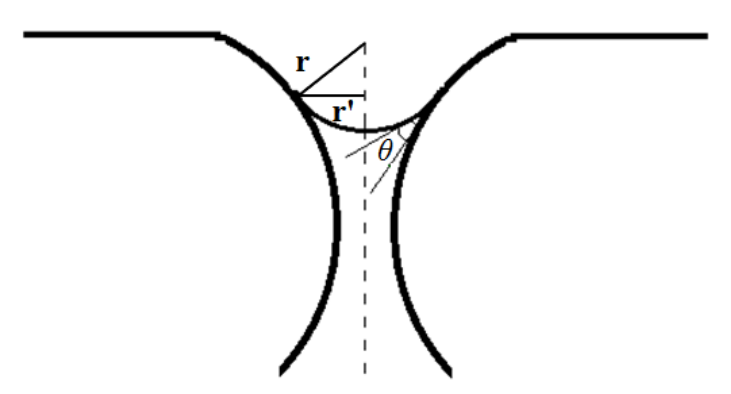

Figure 6 - Simplified model of capillary menisci from [3].

To establish an equilibrium between liquid and gas (vapour), the rate of evaporation must be equal to the rate of condensation, that is when the pressure is equal to the saturation pressure $\left(p=p_{v}\right)$ or in other words, when $R H=100 \%$. When the relative humidity drops, radius of menisci starts to decrease in order to maintain the thermodynamic equilibrium gas-liquid, therefore changing the curvature of menisci. 
Below approximately $R H=70 \%$, surface tension, $\Delta \gamma$ in (Eq. 3) according to Gibbs-Bangham theory [29], increasingly becomes the driving force for the deformation. Here, the deformation is caused by the change in surface tension dependent on the thickness of the adsorbed layers $\Gamma$ and vapour pressure $P$ (Figure 3, Eq. 3). The validity of this theory decreases along with increase of relative humidity and in fact, the discussed mechanism becomes a governing factor for relative humidity below $40 \%$, while above $70 \%$ it almost diminishes completely.

$$
\Delta \gamma=\mathrm{R} T \int_{0}^{P} \Gamma d(\ln P)
$$

Now it can be observed, that the vapour pressure and pore size are the driving factors, which furthermore means, that shrinkage of concrete body must be to some extent a function of porosity [24]. In order to include the effect of porosity and/or pore size distribution more precisely, Eqs. (1) and (2) can be rewritten and formulated ultimately as for instance in Eq. 4 [21].

$$
\varepsilon_{\text {s.ex }}=-\frac{S_{\mathrm{w}} P_{\mathrm{c}}}{3}\left(\frac{1}{K}-\frac{1}{K_{c}}\right)
$$

Here, $\varepsilon_{\text {s.ex }}$ is measurable shrinkage of concrete body, $S_{w} P_{c}$ depict generalized capillary pressure for a given porosity. $K_{c}$ is the elastic modulus of solid [Pa], $K$ is elastic modulus of porous body, $S_{w}$ - degree of saturation and $P_{c^{-}}$-capillary pressure $[\mathrm{Pa}]$.

Other approach has been presented in [42], where the deformation of the solid body at time $t \varepsilon_{s . e x}(t)$ was given as in Eq. 5.

$$
\varepsilon_{\text {s.ex }}(t)=(-v) b\left(\frac{S_{\mathrm{w}} P_{\mathrm{c}}}{E}+\int_{t^{\prime}}^{t} J\left(t-t^{\prime}, t^{\prime}\right) \frac{d\left(S_{w} P_{c}\right)}{d t^{\prime}} d t^{\prime}\right)
$$

Where the $v$ is Poisson's ratio, $b$ - Biot's coefficient, $E$ - modulus of elasticity of solid skeleton and $J$ is a compliance function. In order to quantify the effect of self-restraint due to non-uniform moisture profile (eigenstresses) and restraint from aggregates with unhydrated cement particles, advanced numerical simulation is required as given for instance in [44].

Capillary theory according to above, stands in opposition to the well-known relation between w/c and the drying shrinkage as a higher amount of water is known to cause a coarser pore system, yet also higher shrinkage [30]. However, according to the authors' knowledge, there is no precise explanation of this behaviour. Ye [21] suggested two possible reasons: firstly, the saturation degree $S_{w}$ (Eq. 4) assumes the existence of water only in capillary form, while for low w/c higher water content may be contained in nano and gel pores, where capillary theory is not applicable. Secondly, a possible solution given in [21] is that the viscoelastic response during desiccation (also influenced by $\mathrm{w} / \mathrm{c}$ ) is overwhelming in comparison with shrinkage. Thus, it is probable that the structural effects of specimens' size are in fact affecting the external measurement. It is likely that the general phenomena could comprise both factors, but it is very likely that other mechanisms play a role. Now, neither capillary theory, nor the tension surface approach is able to explain the increase in tensile strength after soft drying or increase in creep. Therefore, it is plausible that the disjoining pressure is active on that level as well, as Bažant suggested it [31]. One has to notice, that according to [31], any change in internal relative humidity is followed by a change in disjoining pressure, due to extremely small distances in the gel pores. Thus, such withdraw of disjoining pressure could affect beneficially both creep and strength of concrete during soft drying [31]. 
Despite the presence of autogenous shrinkage due to the self-desiccation, concrete undergoes drying shrinkage, which, excluding very dense matrices of HPC and UHPC, creates the main bulk of present deformations. If the mix is supplied with a high amount of water, in presence of coarse pore system, autogenous shrinkage is negligible or rather indistinguishable from the drying, that becomes the only driving factor for the shrinkage. A limiting value of $\mathrm{w} / \mathrm{c}$ ratio when the drying shrinkage becomes dominant is reported differently, however w/c ratio 0.4-0.5 is usually given [32]. Since the driving factor here is drying, it has to be primarily governed by the ambient humidity and element thickness, while the temperature is rather a secondary factor [33].

Thin elements, such as concrete overlays, dry within several months, while it takes years for thick members before equilibrium with environment establishes [34;35]. According to the equations of mass transport, solely time of drying should be affected, but not the ultimate deformation. Such statement is usually presented in the model codes [25;35;36;37] and is also covered by a number of experimental results [37;38]. This, however, stands in opposition to the famous results found by L'Hermite [40] or Hansen and Mattock [41] who measured different final deformations on much thicker specimens. This peculiarity is known as the size effect, and it is usually considered to be noticeable in elements when the relative thickness $h_{0}$ is higher than $100 \mathrm{~mm}$ [63]. Although in most cases, thickness of overlays does not exceed the mentioned value. In some cases, overlays even thicker than 200mm were found with use of BaTMan database as well [92].

Several explanations of the size effect have been given in past. The main source is usually attributed to a non-uniform gradient of stresses, accompanied by creep (relaxation) and fracturing of superficial part of specimen, however exact prediction of ultimate deformation is still lacking [42]. The reason might rather be in the higher heat of hydration inside element, leading to a change in sorption isotherm [43]. Here, however, despite change in saturation degree, mechanical properties and creep are affected as well, giving opposite results to the effect of change in sorption isotherm. On the other hand, development of heat due to hydration in thin overlays is negligible, thus the source of size effect in concrete body must be a result of moisture gradients, microcracking and drying creep and should be considered from that perspective.

\subsection{Influence of pore structure, hydration and effect of additives}

The spectrum of admixtures and additives is broad, thus a review would require comprehensive text to be presented and in fact, a separate text. Information on binders' effect can be found in e.g. NU database [25], in models of Bažant and co-workers [25] or in studies of Linmei and Farzdania [45], giving general overview. Reviews are also given by Hooton et al. [46], Tazawa [47] and by Khayat [48]. Two main effects have to be considered: initial pore distribution, for instance fine particles of silica fume are known to increase the shrinkage due to refinement of porosity and solidifing products (Figure 4, Eq. 1).

The hydration is known to be affected by external factors such as temperature, humidity and internal factors e.g. fineness of the binder. The fineness of the binder is known to increase the early age shrinkage leading to higher risk of cracking [49]. Other experimental confirmations have been provided for instance by Tazawa and Miazawa who investigated effect of fineness on autogenous deformation of blended cements [47]. A high surface contact area and higher rate of hydration, results in a higher basic shrinkage and in a decrease of creep as hydration products quickly solidifies onto existing pore system [50]. One has to observe, that change in the final 
shrinkage (with drying) does not occur or is barely noticeable [32] (after Bennett and Loat [51]). The drying is a very slow process, therefore final degree of hydration is usually very similar. On the other hand, changing a gypsum content must obviously affect the deformation [49]. Since the later hydration is governed by the diffusion, with driving potential depending on internal humidity [24;33], Bentz suggested a reconsideration of finer cements as binder in HPC [52]. It was shown that for low w/c, ultimate degree of hydration becomes independent of w/c and thus the coarse cements provides larger pores giving more "curable" system.

As given in previous paragraphs, the external deformation is mainly determined by pore size distribution (PSD). Here however, PSD is not the only factor as the capillary porosity influence the permeability of the structure. Because of the fact that in gel pores, adsorption is strong due to very small pore dimensions, effect of gel pores on the moisture transport is negligible. Parts of capillary pores are also so-called inkbottle pores, which further cause an evident hysteresis in sorption isotherm and causing pore blocking effect. Taking into account the Kelvin-Laplace equation, while adsorption is governed by large radius of theoretical sphere, desorption is controlled by curvature of meniscus in the narrow neck. Thus desorption and emptying of cavity (percolation through the neck) can occur only at a low pressure [53]. Here the largest effect is w/c ratio [54;55], yet presence of pozzolana is not without significance. Zhuquing [56;57], studied the effect of fly ash on development of pore structure and permeability. Despite higher initial capillary porosity, after approximately 180 days of curing, permeability of concrete significantly decreased, as the hollow shell cavities appeared.

\section{5}

\section{Effect of internal restraining from the aggregate}

Shrinkage of concrete or mortar is always influenced by internal restraint due to the presence of aggregates, calcium hydroxide and unhydrated cement. While the aggregates give substantial effects as shown in $[58 ; 59 ; 60]$, the other parts have a rather minor effect. It is known that shrinkage of cement paste is affected by properties of used rock, amount of aggregate in comparison with amount of cement paste and size of used grains $[58 ; 59 ; 60]$.

In a study of Troxell [59], effect of paste amount on shrinkage has been evaluated experimentally, giving a relation in form of a power function. A similar function was obtained by Wendner and Bažant in a calibration of test results [25]. The effect of characteristics was usually considered solely on the level of its elasticity as in famous study of Pickett [58] and later by Hobbs [60]. It is also likely that aggregates have an impact on the process of drying as presented in [25], which is rather of two folded nature. Despite the material transport properties, diffusion would be affected by the presence of microcracks in the interface zone with aggregates. Bisschop [61] suggested however, that the rate of drying, affected by the presence of microcracks, does not exceed $10 \%$, making it a negligible factor. A study of Troxell [59], shows that shrinkage is significantly affected by the size of aggregates due to the local restraining conditions around the grain and induced eigenstresses by shrinking paste. In such circumstances, for larger aggregates, cracks wouldn't be oriented solely for the drying surface, as given for instance in studies of Bisschop and Van Mier [61;62]. Considering this effect in the design phase is impossible however, and as far, this effect should be captured empirically for each aggregate-size composition.

3.

\section{PREDICTION MODELS OF SHRINKAGE}

Several models are given in both codes and literature, just to mention a few $[16,25,36,37,63]$. Probably the most sophisticated model as far, has been given in B4 [25], a further enhancement 
to the B3 [16] approach that comprises both shrinkage and creep of concrete. Moreover, it has to be noticed that the B4 model is featured with several theories, i.e. solidification theory, microprestress theory, activation energy concepts, damage models for microcracks and moisture diffusion theory, and thus it is probably the most advanced engineering approach. In addition, the model has been optimized according to a significant number (more than 1000) of test results for shrinkage and creep, therefore B4 has been chosen as a reference model in herein paper. Although vast contribution has been paid to the abovementioned model, in similarity to other models, B4 omitts simultaneous effect of drying and self-desiccation, which becomes more pronounced in thin elements such as overlays.

\subsection{Autogenous shrinkage}

Several models regarding autogenous shrinkage, often denoted as basic shrinkage, have been presented in past. For instance, Tazawa [18] connected shrinkage with strength development and a similar approach can be found in some codes [63]. Although this approach omits the effect of external factors through the direct of expression of time, it can easily be replaced with equivalent time obtained with equations given by Jonasson for instance [64]. A prediction model that directly comprises maturity concept was given by Hedlund [65]. It has to be noticed, that, since it is only basic shrinkage that is considered in this model, the maturity function becomes a function of only one variable and can be presented in a form as given in i.e. [64]. In addition, effect of various compositions with addition of pozzolana has been included and applicability of this model comprises both normal concrete and HPC. A drawback of those approaches was later on discussed by Sellevold and Bjotengraad [66], as maturity concept for temperature does not respond to the effect of varying temperature, especially during cooling phase during the hardening of e.g. massive structures.

Important to notice is, that self-desiccation is in fact, a self-stopping process showing asymptotic trend once it occurs simultaneously with drying, and for thin members such as pavements, reaches final value in natural conditions within several first months [25]. Therefore, one has to know in fact when the hydration would stop, otherwise basic contraction can be significantly overestimated. Ultimately, in B4 approach, Bažant introduced maturity concept and asymptotic behaviour of the strain function [25], which is by more likely to depict occurring process in a way that is more suitable.

\section{2}

\section{Drying shrinkage}

It is well known that the shrinkage deformation is proportional to the change in evaporable water content in an almost linear relation. However, during drying, the concrete body establishes quilibrium in vapour pressure. Any attempt to relate it with external ambient conditions requires establishing a sorption isotherm. Therefore, external shinkage deformation could be written as follows

$$
\Delta \varepsilon_{\mathrm{sh}}=\Delta w(R H) k_{\mathrm{sh}}
$$

where $\Delta w(R H)$ is a sorption isotherm, $\varepsilon_{s h}$ is a final drying shrinkage strain [\%o] and $k_{s h}$ is a material parameter for shrinkage deformation and $\Delta w$ - amount of removable water that underwent desiccation [-]. One has to observe that as long as hydration proceeds, not only the amount of measurable evaporable water changes and decreases in time, but also the path of drying starts to 
change [24]. Therefore the conception proposed by Bažant, to measure loss of weight after reaching ultimate hydration degree, gives discrepancy in prediction of the drying path. Now, the dominant factor is hydration and because it is affected by internal humidity, temperature and amount of solidified products, time of expostion to drying is not without the meaning, Figure 7. In other words, concrete cured for one day undergoes different deformations than cured for e.g. 28 days. Contradictionary results were obtained experimentally by Beushausen [67] as the ultimate deformation became almost independet of curing time, here, however, high water-cement ratio has to be considered as well. Furthermore, it has been shown by Mjörnell [24], that for high w/c ratios, degree of hydration $\alpha$ has a negleglible influence on the sorption iotherm, in scope of normal drying (i.e. 40 - 95\% of humidity).

A typical expression for a sorption isotherm given in codes is $1-(R H / 98)^{3}$, also as given in Eq. 8 [35;36;37]. Below aproximately $40 \%$ of relative humidity, gel pores start to be emptied and this usually depicts as an infliction point on the isotherm. Hance this part of isotherm is not taken into consideration. In order to capture this infliction point, Bažant [16,35] suggested to use the coefficient 0.75 (Eq. 7) in order to relate the abovementioned expresion with the water loss:

$$
\Delta \varepsilon_{\mathrm{sh}}=k_{\mathrm{sh}}\left[w_{0}-w(R H)\right]=k_{\mathrm{sh}} w_{0}\left[1-0.75\left(1-\left(\frac{R H}{98}\right)^{3}\right)\right]
$$

where $R H$ - ambient humidity [\%],

Now, assuming that for $w=w_{0}$ (before drying) shrinkage deformation is equal to zero, we obtain:

$$
\varepsilon_{\text {sh }}=-k_{\text {sh.ult }}\left[1-\left(\frac{R H}{98}\right)^{3}\right]
$$

where $k_{\text {sh.ult }}$ is material parameter. It has to be observed that the presented equation is not always true. One has to consider that an isotherm varies significantly, depending on w/c ratio and hydration degree, as given in Figure 7 for instance, and many of them can be found in the work of Mjörnell [24].

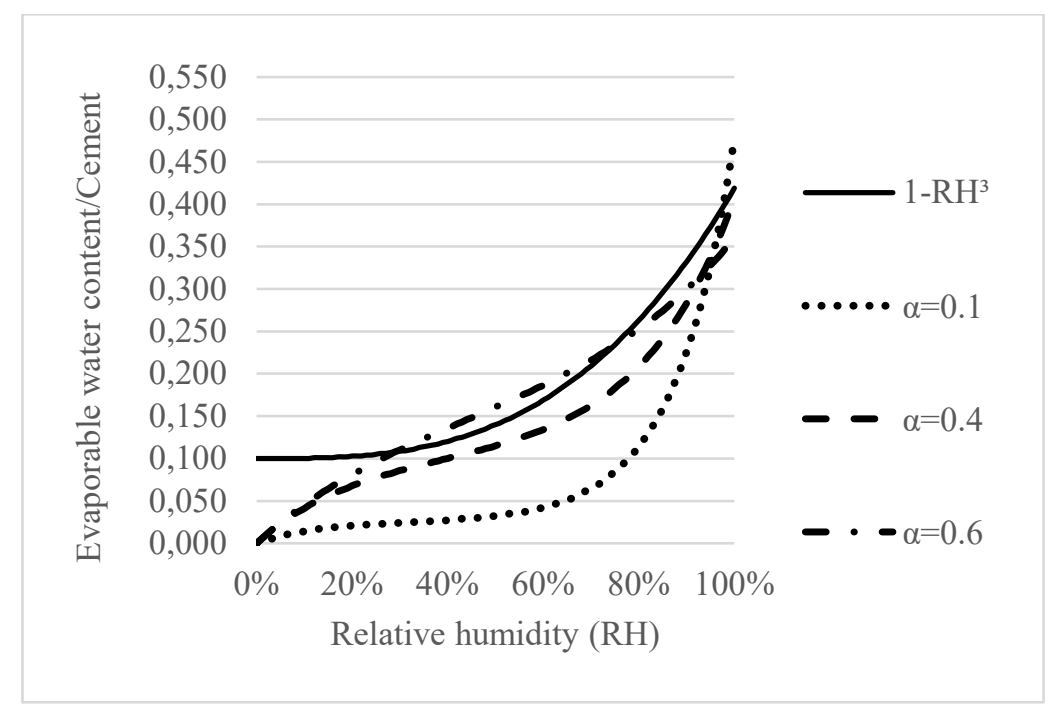

Figure 7 - Sorption isotherms calculated for different degree of hydration $\alpha$ according to [24] and with normative function 1-(RH/98) ${ }^{3}$. 
As a significant shrinkage may start to build up within the first days and humidity achieves equilibrium with the ambient climate within first several months, an appropriate creep prediction over the whole range of hardening time becomes crucial when calculating restraining stresses. Although creep of concrete is traditionally considered from a negative perspective, e.g. in cases such as load bearing elements, it has a positive effect in presence of restrained deformation for instance in bonded concrete overlays or segments of walls. The creep manifests as the relaxation, which thus induces reduction of occurring restrained stresses. The effect of creep (relaxation) on the possible risk of cracking in concrete overlay is tremendous, therefore suitable prediction becomes a vital factor. To limit possible influencing factors, the nature of creep should be discussed in order to limit influencing factors and to discuss methods of creep prediction. Creep of concrete is usually related to the type of cement, drying during time at which load is applied, type of load and its value. Those will be discussed in the following paragraphs.

\section{1}

\section{Nature of creep}

The very nature of creep is usually attributed to the relocation (diffusion) of water molecules in the pore system under external load, which ultimately results in delayed deformations of concrete members. Although various theoretical explanations have been given in the past [68], yet no clear agreement between them has been achieved $[31 ; 69 ; 70]$. Ulm [71] stated that various mechanisms might be active and suggested that short-term (up to the first 10 days after loading) creep could be a result of water seepage, while long-term creep could have a source in slippage of the C-S-H layers. The seepage theory is the most popular explanation of occurring processes that assumes that the creep has source in water movement due to "squeezing" of pore system, as suggested by Powers.

The water molecules from regions of hindered adsorption (gel pores) move to capillary pores (unhindered regions or regions of free adsorption). At that point, however, the local moisture conditions would have to change. This peculiarity has been discussed by Theiner [72], Wyrzykowski [73], and Tamtsia [68] just to mention a few. On one hand Wyrzykowski recorded change in internal humidity, yet creep is known to occur in immersed conditions as well, as was given by Young [74], as it was pointed out by Theiner [72]. It has to be noticed, that in sealed conditions, due to occurring hydration, pore system is desiccated as well, therefore concrete specimen should be water cured in controlled way, for at least several months in order get rid of any moisture gradients inside the specimen and to obtain perfect imbibition of the specimen.

Bažant $[31 ; 35]$ contradicts the above findings, stating that the gel body is unable to deform in such manner to cause a significant micro diffusion and suggested that creep could have source to some extent in withdrawal of disjoining pressure, which is causing microprestress. It is interesting that the approach developed by Bažant based on the aforementioned theory finds an experimental confirmation in so-called nanoindentation tests for C-S-H phase [75]. The creep rate of this viscous behaviour is independent of loading age $t$ ' but becomes dependent of the age of the concrete, thus the long-term creep must manifest in parallel functions for varying $t^{\prime}$ as given in [76] or in Figure 8. Tests by Ulm and co-workers $[71 ; 75 ; 76]$ indicate directly that later creep and its rate of pure $\mathrm{C}-\mathrm{S}-\mathrm{H}$ phase solely depends on the age of concrete, similarly as it was given in the microprestress solidification theory. 
Nordic Concrete Research - Publ. No. NCR 61 - ISSUE 2 / 2019 - Article 7, pp. 107-129

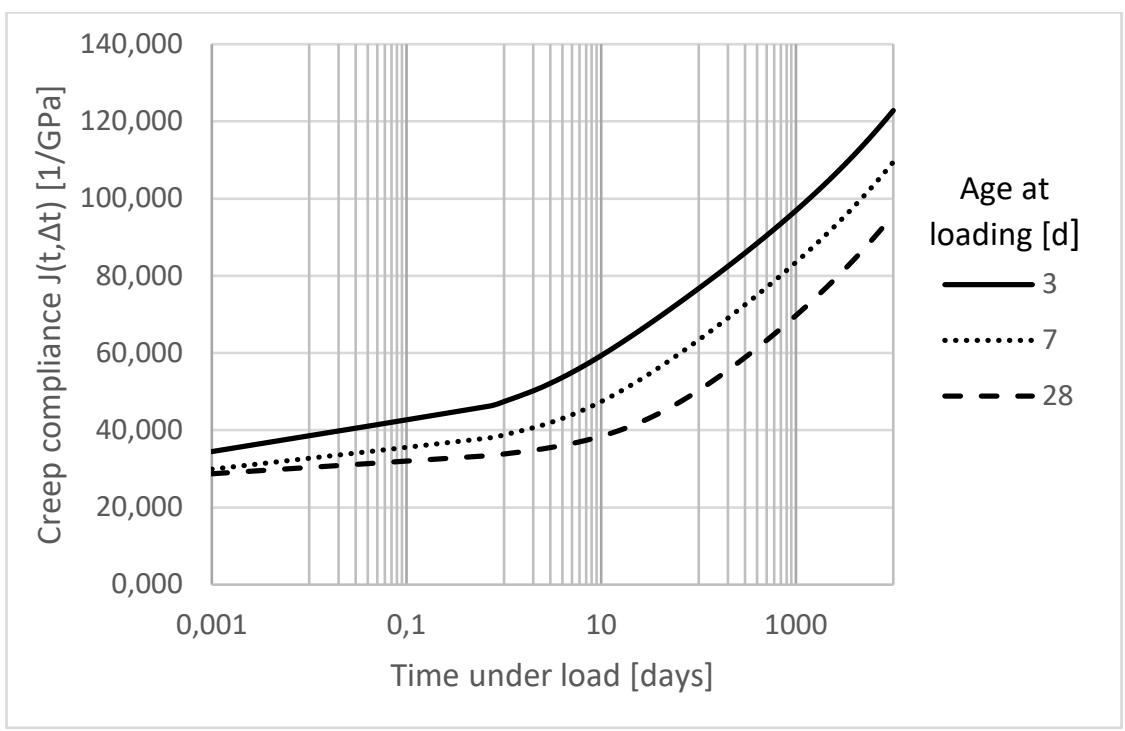

Figure 8 - Compliance functions for concrete loaded at 3, 7 and 28 days of maturity. Calculated according to [25].

\section{2}

\section{Short and long term creep, models of creep.}

The instanteneous and delayd creep deformation of concrete is usually expressed with a compliance function $J$ of deformation for unit of stress as given as:

$$
J\left(t, t^{\prime}\right)=\frac{1}{E\left(t^{\prime}\right)}+\Delta J\left(t-t^{\prime}, t^{\prime}\right)
$$

Where $t^{\prime}$ is time (age) at application of load, $t$ is the age of concrete, $E\left(t^{\prime}\right)$ is modulus of elasticity at application of load.

On the other hand, in case of restrained deformations (shrinkage and thermal dilation), under applied unit deformatrion at time $t$ ', the decreasing stresses in concrete body at time $t$ can be expressed with:

$$
\sigma\left(t, t^{\prime}\right)=\frac{\Delta \varepsilon}{J\left(t, t^{\prime}\right)}=\Delta \varepsilon * R\left(t, t^{\prime}\right)
$$

Where $\sigma\left(t, t^{\prime}\right)$ is induced stress, $\Delta \varepsilon$ applied deformation and $R\left(t, t^{\prime}\right)$ is the relaxation function. It has to be mentioned, the measurable instanteneous deformation already includes creep to some extent as it was stated by Neville [32]. As seen in Eq. 9 the creep deformation depends on two variables: age of concrete at loading $t^{\prime}$ and load duration $t-t^{\prime}$. It is thus more convenient to consider creep at the level of compliance function rate, i.e. $\partial J / \partial t$, which allows distinguishing two basic separate behaviours occurring within first days and later on Figure 9. In literature, those two features are usually considered as short term and long term creep respectively, which leads to well-known log power laws [77;78]. 
Nordic Concrete Research - Publ. No. NCR 61 - ISSUE 2 / 2019 - Article 7, pp. 107-129

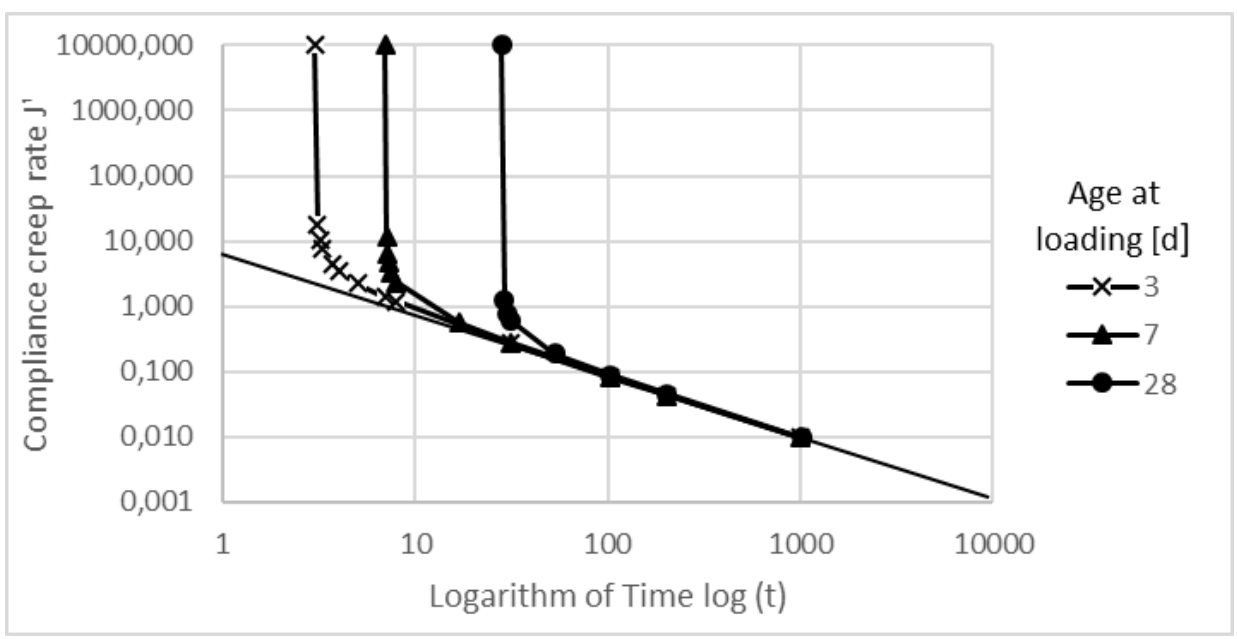

Figure 9 - Curves of basic creep rate at various ages. Caclulated according to [25]

The most problematic aspect is short-term creep, which mostly depends on amount of solidified products and significant differences, can thus be observed once the concrete specimen is loaded at an early age, usually below 1 day. Here it is important to observe that significant stresses may build up at early age when concrete is restrained, and wrong estimation of creep gives an inappropriate relaxation spectra [79]. Such problems are reported in $[78 ; 79 ; 80]$ in attempts to describe early age creep. Østergaard [81], in order to modify solidification theory approach, suggested reduction of real time with structural setting time.

Since the hydration proceeds rapidly within the first day, turning from liquid through setting into solid and drastically changing modulus of elasticity, the possible explanation of that peculiarity could be attributed to the setting time. Emborg [80] modified Triple Power Law by introduction of two exponential functions for early age. Here however, independence of loading age, long-term creep becomes violated. Larson [78] noticed similar problem in linear logarithmic approach. If $\partial J / \partial t$ would be formulated as two linear functions of age at loading and age, long-term behaviour becomes strongly disturbed. The reason lies in the change of rate coefficients, which are functions of age at loading.

\section{3}

\section{Influence of drying}

The drying has a paradoxical effect on the creep as the final deformation exceeds combined basic creep and the drying shrinkage. This peculiarity is known as the Pickett effect, already mentioned, which involves three basic mechanisms: skin microcracking due to the differential shrinkage, basic creep and stress-induced shrinkage [82]. While uniaxially loaded specimens presence of Pickett effect itself, they do not distinguish the magnitude of each of those components. In order to eliminate the effect of shrinkage, Bažant suggested measurement of curvature at eccentrically loading [82]. Here eccentricity allows eliminating or introducing tensile stresses in the specimen. In fact, microcracking practically does not occur in compressive load up to $40 \%$, as at this state, any tensile stresses are overwhelmed by compression and thus microcracks cannot develop [82]. Since a perfect sealing is almost impossible, partial drying may be a reason for discrepancies between compressive and tensile measurements, as discussed in next paragraph.

The effect of stress-induced shrinkage has likely a source in breaking hydrogen bonds between water molecules in hindered adsorption regions, enhancing ability to slide of layers and thus 
increasing creep $[31 ; 68 ; 70]$. From a practical perspective in many applications, effect of drying is of large importance, as according to Acker and Ulm [71], the relative creep may become up to several times higher and is primary governed by w/c ratio [71;84]. In addition, it has to be kept in mind that overlay usually undergoes cyclic wetting and drying due to the rainfall, and thus contribution of drying to the relaxation should be larger.

\subsection{Tensile versus compressive loading.}

Due to the shrinkage, tensile stresses appear in overlay, the measurement of creep in tension may be problematic however, especially at early age. Moreover, because the tensile strength is relatively small, displacement under the load is also very small and effect of shrinkage on possible error of measurement becomes significant. Thus, reported tests on tensile creep are very limited for this stage and it is usually considered that creep occurring in tension and compression are equal to each other.

According to several investigations [85;86], the magnitude of creep in both cases may be more or less in the same range. However, for low loads i.e. below about $50 \%$ of strength, increase in creep in respect to compression could be observed, likely due to increased significance of microcracking [87]. Another reason for those small discrepancies, especially at early age, could be connected with difference in elasticity modulus as given for instance by Ji [88] or Klausen [85]. However, the differences have been observed to be about $10 \%$ and for simplicity of engineering approach, one can assume creep in tension and compression to be equal.

\section{5}

\section{Effect of w/c ratio.}

Creep of concrete is largely dependent on the concrete composition; i.e. presence of various additives, amount of paste, etc. The largest factor is the w/c ratio. It is generally well known, that creep of concrete, both short and long term, increases along with increased w/c ratio in similarity to the elastic deformation. From a short-term perspective, creep is excessively connected with amount of solidified hydrates, as discussed in previous paragraphs. In a late study by Ulm, effect of low long-term creep for low w/c ratio has been explained by granular theory and evaluated experimentally by so-called nanoindentation [75]. According to the theory, creep rate (rearrangement of C-S-H globules) is depending on distribution of C-S-H density. In other words, for low w/c ratios, denser C-S-H can be observed, which stands in good agreement with experimental results by Pigeon et al. [89;90]. Contradictory results on the other hand were found in work of Altoubat [91], who obtained the lowest specific creep (creep strain per unit of stress) for specimens with highest w/c ratio. However, lack of consistency within results undermines plausibility of mentioned tests.

\section{DISCUSSION AND CONCLUSIONS}

Over the last few decades, technology of bonded concrete overlays for bridges has significantly been developed as regard design, material choice and execution. So far however, drawbacks present in this solution for deck covers have not been eliminated to a satisfying level and shrinkage induced cracking is pointed out as a primary factor of deterioration. Shrinkage during plastic and hardening stage is the driving mechanism of restrained stresses. Thus, a better understanding of their mechanisms and suitable methods of their estimation are essential for successful 
investments. Furthermore, restraining conditions and visco-elastic response of the overlay has large effect on behaviour of the overlay. It is likely therefore, that suitable choice of season for performance of works, choice of applied in field methods have a large influence of the durability and long-term behaviour of an overlay, securing final quality of work.

With available vast spectrum of prediction models, fitting of experimental results of shrinkage deformations is no longer a large problem. A challenge for comprehensive approach however, lies within correct estimation of crack-risk and time of failure, if such is intended to obtain. Therefore, it could be mentioned that a robust design practice regarding concrete covers, especially on bridge decks, requires suitable methods of shrinkage modelling that would respond to material parameters and different environmental conditions. It is also important, that such analysis must involve varying external conditions with possibility to perform a parametric case study in respect to crucial factors such as humidity, geometry and its structural effects, temperature etc. Several approaches on shrinkage modelling based on poromechanics have been developed as far, such are usually too difficult and too complex to handle in day-to-day operations.

Although this paper is not focused on the plastic shrinkage, its significance and contribution to the discussed problem cannot be omitted. It is very likely that either the rate of assumed evaporation is underestimated, or procedures performed at site do not suffice to secure a good quality of concrete works performance. Independent of the reason behind plastic shrinkage cracking, further research in this subject would be required.

It is shown within this work, that establishing a comprehensive approach for the drying creep and early age creep is a cumbersome task, and in practice solvable e.g. with use of B4 model by Bažant et al. [25]. However, it is not shown to which extent such prediction models agree with experimental results performed for local materials and binders. In addition, a modelling approach is required in order to evaluate the effect of shrinkage on creep in a more comprehensive way, by considering shrinkage as an effect of desiccation. Also, one has to observe the importance of drying process onto the occurring relaxation as well as the importance of early age creep.

The crack risk and types of cracks in case of stress-strength failure mainly depends on the bonding conditions between old and young concrete. It is known that methods of preparation strongly affects future bond, as well as performance of the concrete overlay. Experimental results suggest that, exposition of aggregate surface is more important than the process in which effective surface area is increased. From practical perspective, general conclusions drawn by Morgan [14] regarding SSD condition of substrate should be considered as optimal for securing good bond between old and new concrete.

Although several investigations have been focused on the bond between SCC and reinforcement, there is very limited number of tests showing how the high workability of SCC and speed of casting can secure the bond between the substrate and the overlay.

Furthermore, robust and transparent methods requires also a suitable test set-up for calibration of models. The execution of half-scale or full-scale tests is however expensive and difficult in performance. Hence, it is necessary to develop a new and reliable equipment for crack-risk prediction. 
Nordic Concrete Research - Publ. No. NCR 61 - ISSUE 2 / 2019 - Article 7, pp. 107-129

\section{REFERENCES}

1. Edwards Y: "Hållbara brobaneplattor-tätskikt: state of the art." Report, Swedish Cement \& Concrete Research Institute, Stockholm, Sweden, 2011, pp. 32-72. (In Swedish.)

2. Yusuf Hassan A: "Slitbanebetong för broar: Inventering och inverkan av krympning." Master thesis, Luleå University of Technology, Dept. of Civil, Environmental and Natural Resources Engineering, Luleå, Sweden, 2012, pp. 13-15. (In Swedish.)

3. Sayahi F: "Plastic Shrinkage Cracking in Concrete: Mitigation and Modelling." Doctoral thesis, Luleå University of Technology, Dept. of Civil, Environmental and Natural Resources Engineering, Luleå, Sweden, 2019.

4. Carlswärd J \& Emborg M: "Shrinkage cracking of thin concrete overlays." Nordic Concrete Research, Vol. 50, 2014, pp. 355-359.

5. Jonasson J-E: "Datorprogram för icke-linjära beräkningar i betong med hänsyn till svinn, krypning och temperatur." Report, Swedish Cement \& Concrete Research Institute, Stockholm, Sweden, 1977, pp. 105-108.

6. Birkeland HW. "Differential shrinkage in composite beams." ACI Journal Proceedings, Vol. 56, No. 5, 1960, pp. 1123-1136.

7. Silfwerbrand J: "Improving Concrete Bond in Repaired Bridge Decks." Concrete International, Vol. 12, No 9, 1990, pp. 61-66.

8. Silfwerbrand J: "Bonded concrete overlays - Research needs." Proceedings, $2^{\text {nd }}$ International RILEM Symposium on Advances in Concrete through Science and Engineering, Sept. 11-16, Quebec City, Canada, pp. 193-206.

9. Silfwerbrand J: "Stresses and strains in composite concrete beams subjected to differential shrinkage." Structural Journal 94, 1997, pp. 347-353.

10. Courard L, Piotrowski T \& Garbacz A: "Near-to-surface properties affecting bond strength in concrete repair." Cement and Concrete Composites, Vol. 46, 2014, pp. 73-80.

11. Bissonnette B, Courard L, Fowler D W \& Granju J: "Bonded Cement-based Material Overlays for the Repair, the Lining or the Strengthening of Slabs or Pavements: State-ofthe-art." Report of the RILEM Technical Committee 193-RLS, Springer Science \& Business Media, 2011, pp. 51-76.

12. Sadowski Ł, Żak A \& Hoła J: "Multi-sensor evaluation of the concrete within the interlayer bond with regard to pull-off adhesion." Archives of Civil and Mechanical Engineering, Vol. 18, 2018, pp. 573-582.

13. Beushausen H, Höhlig B \& Talotti M: "The influence of substrate moisture preparation on bond strength of concrete overlays and the microstructure of the OTZ." Cement and Concrete Research, Vol. 92, 2017, pp. 84-91.

14. Morgan D R: "Compatibility of concrete repair materials and systems." Construction and Building Materials, Vol. 10, 1996, pp. 57-67.

15. Carlswärd J: "Shrinkage Cracking of Steel Fibre Reinforced Self Compacting Concrete Overlays: Test Methods and Theoretical Modelling: Test Methods and Theoretical Modelling." Doctoral thesis, Luleå University of Technology, Dept. of Civil, Environmental and Natural Resources Engineering, Luleå, Sweden, 2006, pp. 93-95.

16. Bažant Z P \& Baweja. S: "Creep and shrinkage prediction model for analysis and design of concrete structures: Model B3." ACI Special Publications, Vol. 194, 2000, pp. 1-84.

17. Taylor H F: "Cement chemistry", Thomas Telford, 1990, pp. 335-337.

18. Tazawa E, Miyazawa S \& Kasai. T: "Chemical shrinkage and autogenous shrinkage of hydrating cement paste." Cement and Concrete Research, Vol. 25, 1995, pp. 288-292,

19. Nilsson L \& Johansson B: Crack-Free-Con. "Data från krympexperiment", Report TVBM 3171, Lund University, Div. of Building Materials, Lund, Sweden, 2013. (In Swedish.) 
20. Jensen $\mathrm{O}$ M \& Hansen P F: "A dilatometer for measuring autogenous deformation in hardening Portland cement paste." Materials and Structures, Vol. 28, 1995, pp. 406-409.

21. Ye H \& Radlińska A: "A review and comparative study of existing shrinkage prediction models for Portland and non-Portland cementitious materials." Advances in Materials Science and Engineering, Vol. 122, 2016, pp. 594-606.

22. Lura P, Jensen O M \& van Breugel K.: "Autogenous shrinkage in high-performance cement paste: An evaluation of basic mechanisms." Cement and Concrete Research, Vol. 33, 2003, pp. 223-232 .

23. Aili A, Vandamme M, Torrenti J \& Masson B: "Is long-term autogenous shrinkage a creep phenomenon induced by capillary effects due to self-desiccation?" Cement and Concrete Research, Vol. 108, 2018, pp. 186-200.

24. Mjörnell K N: "Moisture Conditions in High Performance Concrete." Doctoral thesis, Chalmers University of Technology, Dept. of Building Materials, Göteborg, Sweden, 1997, pp. 34-40.

25. Physics of Creep, Shrinkage, and Durability of Concrete: A Tribute to Wendner R, Hubler M H \& Bažant Z P: "The B4 model for multi-decade creep and shrinkage prediction." Proceedings, $9^{\text {th }}$ international conference on creep, shrinkage and durability mechanics, "Mechanics and Zdeněk P. Bažant". Cambridge, MA, USA, Sept. 2013.

26. Abuhaikal M, Ioannidou K, Petersen T, Pellenq R J \& Ulm F: "Le Châtelier's conjecture: Measurement of colloidal eigenstresses in chemically reactive materials." Journal of the Mechanics and Physics of Solids, Vol. 112, 2018, pp. 334-344.

27. Hansen W: "Drying shrinkage mechanisms in Portland cement paste." Journal of the American Ceramic Society, Vol.70, 1987, pp. 323-328.

28. Hua C, Acker P \& Ehrlacher A: "Analyses and models of the autogenous shrinkage of hardening cement paste: I. Modelling at macroscopic scale." Cement and Concrete Research, Vol. 25, 1995, pp. 1457-1468.

29. Bangham D H, Fakhoury N \& Mohamed A F: "The swelling of charcoal. Part II.-Some factors controlling the expansion caused by water, benzene and pyridine vapours." Proceedings, The Royal Society of London. Series A, Containing Papers of a Mathematical and Physical Character, Vol. 138, 1932, pp. 162-183.

30. Odman S: "Effects of variations in volume, surface area exposed to drying, and composition of concrete on shrinkage." Proceedings, Colloquium on the shrinkage of hydraulic concretes, Madrid Spain, 1968, pp. 20.

31. Bažant Z P, Hauggaard A B, Baweja S \& Ulm F: "Microprestress-solidification theory for concrete creep. I: Aging and drying effects." Journal of Engineering Mechanics, Vol. 123, 1997, pp. 1188-1194.

32. Neville A M: "Właściwości Betonu", $4^{\text {th }}$ edition, Polski Cement, 2000. pp. 441-455. (In Polish.)

33. Jonasson J E, Mjörnell K \& Carlsson C A: "Modeling of Simultaneous Temperature and Moisture transportation in modern concrete." Proceedings. International RILEM Symposium on Concrete Modelling ConMod. Delft, The Netherlands, Vol. 8, 2008 , pp. 665-672.

34. Ross A D: "Shape, size and shrinkage." Concrete and Constructional Engineering, Vol. 39, 1944, pp. 193-199.

35. Bažant Z P \& Murphy W P: "Creep and shrinkage prediction model for analysis and design of concrete structures-model B3." Matériaux et constructions, Vol. 28, 1995, pp. 357-365.

36. ACI. "Prediction of creep, shrinkage, and temperature effects in concrete structures". ACI 209r-92, American Concrete Institute, Farmington Hills, MI, USA, 1992.

37. CEB-FIP, M.C. Design code. Comite Euro International du Beton, Lausanne, Switzerland, 1990, pp. 51-59. 
38. Almudaiheem J A \& Hansen W: "Effect of specimen size and shape on drying shrinkage of concrete." Materials Journal, Vol. 84, 1987, pp. 130-135.

39. Hobbs D W \& Mears A R: "The influence of specimen geometry upon weight change and shrinkage of air-dried mortar specimens." Magazine of Concrete Research, Vol. 23, 1971, pp. 89-98.

40. L'Hermite R G: "Nouveaux resultants de recherches sur la deformation et la rupture du beton." Annales De 1'Institut Technique Du Batiment Et Des Travaux Publics, Vol. 18, 1965, pp. 325-359. (In French.)

41. Hansen T C \& Mattock A H: "Influence of Size and Shape of Member on the Shrinkage and Creep of Concrete." Proceedings ACI, Vol. 63, No. 2, 1966, pp. 267-290.

42. Benboudjema F \& Torrenti. J: "Modelling desiccation shrinkage of large structures." InEPJ Web of Conferences, Vol. 56, 2013, pp. 02001.

43. Torrenti J M \& Benboudjema F: "Desiccation Shrinkage of Large Structures: Is there a Size Effect?" Proceedings, $9^{\text {th }}$ international conference on creep, shrinkage and durability mechanics, "Mechanics and Zdeněk P. Bažant". Cambridge, MA, USA, Sept. 2013., pp. 404-411.

44. Havlásek P, Jirásek M: "Multiscale modeling of drying shrinkage and creep of concrete", Cement and Concrete Research, Vol. 85, July 2016, pp. 55-74.

45. Wu L,Farzadnia N, Shi C, Zhang Z \& Wang H: "Autogenous shrinkage of high performance concrete: A review.", Construction and Building Materials, Vol. 149, 2017, pp. 62-75.

46. Hooton R D, Stanish K \& Prusinski J: "The effect of ground granulated blast furnace slag (slag cement) on the drying shrinkage of concrete-a critical review of the literature." Slag Cement Concrete, 2009, pp. 79-94.

47. Tazawa E \& Miyazawa S: "Influence of constituents and composition on autogenous shrinkage of cementitious materials." Magazine of Concrete Research, Vol. 49, 1997, pp. $15-22$.

48. Khayat K H: "Silica Fume in Concrete-An Overview." ACI Special Publication, Vol. 132, 1992, pp. 835-872.

49. Bentz D P, Jensen O M, Hansen K K, Olesen J F, Stang H \& Haecker C: "Influence of Cement Particle-Size Distribution on Early Age Autogenous Strains and Stresses in Cement-Based Materials.", Journal of the American Ceramic Society, Vol. 84, 2001, pp. 129-135.

50. Neville A M: "Role of cement in the creep of mortar." ACI Journal Proceedings, Vol. 55, 1959, pp. 963-984.

51. Bennett E W \& Loat D R: "Shrinkage and creep of concrete as affected by the fineness of Portland cement", Magazine of Concrete Research, Vol. 22, 1970, pp. 69-78.

52. Bentz D P \& Haecker C J: "An argument for using coarse cements in high-performance concretes." Cement and Concrete Research, Vol. 29, 1999, pp. 615-618.

53. Ravikovitch P I \& Neimark A V: "Experimental confirmation of different mechanisms of evaporation from ink-bottle type pores: equilibrium, pore blocking, and cavitation." Langmuir, Vol. 18, 2002, pp. 9830-9837.

54. Zeng Q, Li K, Fen-Chong T \& Dangla P: "Pore structure characterization of cement pastes blended with high-volume fly-ash." Cement and Concrete Research, Vol. 42, 2012, pp. 194204.

55. Chen X, Wu S \& Zhou J: "Experimental study and analytical model for pore structure of hydrated cement paste." Applied Clay Science, Vol. 101, 2014, pp. 159-167.

56. $\mathrm{Yu} \mathrm{Z,} \mathrm{Ma} \mathrm{J,} \mathrm{Ye} \mathrm{G,} \mathrm{van} \mathrm{Breugel} \mathrm{K} \mathrm{\&} \mathrm{Shen} \mathrm{X:} \mathrm{"Effect} \mathrm{of} \mathrm{fly} \mathrm{ash} \mathrm{on} \mathrm{the} \mathrm{pore} \mathrm{structure} \mathrm{of}$ cement paste under a curing period of 3 years." Construction and Building Materials, Vol. 144, 2017, pp. 493-501. 
57. Yu Z, Ni C, Tang M \& Shen X: "Relationship between water permeability and pore structure of Portland cement paste blended with fly ash." Construction and Building Materials, Vol. 175, 2018, pp. 458-466.

58. Pickett G: "Effect of aggregate on shrinkage of concrete and a hypothesis concerning shrinkage." ACI Journal Proceedings, Vol. 52, 1956, pp. 581-590.

59. Troxell G E, Davis H E \& Kelly J W: "Composition and properties of concrete." $2^{\text {nd }}$ edition, McGraw-Hill Book Company, 1968.

60. Hobbs D W: "Influence of aggregate restraint on the shrinkage of concrete." ACI Journal Proceedings, Vol. 71, 1974, pp. 445-450.

61. Bisschop J \& van Mier J G: "Effect of aggregates and microcracks on the drying rate of cementitious composites". Cement and Concrete Research, Vol. 38, 2008, pp. 1190-1196.

62. Bisschop J \& Van Mier J G: "Effect of aggregates on drying shrinkage microcracking in cement-based composites." Materials and Structures, Vol. 35, 2002, pp. 453-461.

63. EN 1992-1-1: "Eurocode 2: Design of concrete structures - Part 1-1: General rules and rules for buildings." European Committee for standardisation, 2005, pp. 26-29.

64. Jonasson J: "Modelling of Temperature, Moisture and Stresses in Young Concrete." Doctoral Thesis, Luleå University of Technology, Div. of Structural Engineering, Luleå, Sweden, 1994, pp. 47-56.

65. Hedlund H: "Hardening Concrete: Measurements and Evaluation of Non-Elastic Deformation and Associated Restraint Stresses." Doctoral Thesis, Luleå University of Technology, Div. of Structural Engineering, Luleå, Sweden, 2000, pp. 110-135.

66. Bjøntegaard $\varnothing$ \& Sellevold E J: "Thermal Dilation - Autogenous Shrinkage: How to Separate." Proceedings, International Workshop on Autogenous Shrinkage of Concrete, organized by JCI, Hiroshima, Japan, 1999, pp. 245-256.

67. Beushausen H \& Bester N: "The influence of curing on restrained shrinkage cracking of bonded concrete overlays." Cement and Concrete Research, Vol. 87, 2016, pp. 87-96.

68. Tamtsia B T \& Beaudoin JJ: "Basic creep of hardened cement paste. A re-examination of the role of water." Cement and Concrete Research, Vol. 30, 2000, pp. 1465-1475.

69. Powers T C: "A discussion of cement hydration in relation to the curing of concrete." Highway Research Board Proceedings, vol. 27, 1948, pp. 178-188

70. Feldman R F \& Sereda, P J: "A model for hydrated Portland cement paste as deduced from sorption-length change and mechanical properties." Matériaux Et Construction, Vol. 1, 1968, pp. 509-520.

71. Acker P \& Ulm F: "Creep and shrinkage of concrete: physical origins and practical measurements." Nuclear Engineering and Design, Vol. 203, 2001, pp. 143-158.

72. Theiner,Y, Drexel M, Neuner M, \& Hofstetter G: "Comprehensive study of concrete creep, shrinkage, and water content evolution under sealed and drying conditions." Strain, 2017, 53:e12223.

73. Wyrzykowski M \& Lura P: "The effect of external load on internal relative humidity in concrete." Cement and Concrete Research, Vol. 65, 2014, pp. 58-63.

74. Young J F: "An Assessment of the Influence of Microstructure on Time-Dependent Deformations of Hardened Cement Paste." Proceedings, First Australian Conference on Engineering Materials, Sidney 1974, pp. 3-28

75. Vandamme M \& Ulm F: "Nanoindentation investigation of creep properties of calcium silicate hydrates." Cement and Concrete Research, Vol. 52, 2013, pp. 38-52.

76. Bažant Z P \& Jirásek M: "Creep and hygrothermal effects in concrete structures." Vol. 225, Springer, 2018

77. Bažant Z P \& Chern J: "Log double power law for concrete creep." ACI Journal Proceedings, Vol. 82, 1985, pp. 665-675. 
78. Larson M \& Jonasson J-E: "Linear Logarithmic Model for Concrete Creep." Journal of Advanced Concrete Technology, Vol. 1, 2003, pp. 172-187.

79. Hösthagen: A: "Evaluation of material Properties for Young Concrete". Draft Report, Luleå Technical University, Div. of Building Materials and Structural Engineering, Luleå, Sweden, 2019. (To be published).

80. Emborg M: "Thermal Stresses in Concrete Structures at Early Ages." Doctoral Thesis, Luleå University of Technology, Div. of Structural Engineering, Luleå, Sweden, 1989, pp. 99-100.

81. Østergaard L, Lange D A, Altoubat S A \& Stang H: "Tensile basic creep of early-age concrete under constant load." Cement and Concrete Research, Vol. 31, 2001, pp. 18951899.

82. Bažant Z P \& Yunping X I: "Drying creep of concrete: constitutive model and new experiments separating its mechanisms." Materials and Structures, Vol. 27, 1994, pp. 3-14.

83. Bažant Z P \& Raftshol W J: "Effect of cracking in drying and shrinkage specimens", Cement and Concrete Research, Vol. 12, 1982, pp. 209-226.

84. Bissonnette B \& Pigeon M: "Tensile creep at early ages of ordinary, silica fume and fiber reinforced concretes." Cement and Concrete Research, Vol. 25, 1995, pp. 1075-1085.

85. Klausen A E, Kanstad T, Bjøntegaard $\varnothing \&$ Sellevold E J: "Comparison of tensile and compressive creep of fly ash concretes in the hardening phase." Cement and Concrete Research, Vol. 95, 2017, pp. 188-194.

86. Westman G: "Concrete Creep and Thermal Stresses: New Creep Models and their Effects on Stress Development." Licentiate Thesis, Luleå University of Technology, Dept. of Civil, Environmental and Natural Resources Engineering, Luleå, Sweden, 1995, pp. 37-57.

87. Grzybowski M \& Shah S P: "Model to predict cracking in fibre reinforced concrete due to restrained shrinkage." Magazine of Concrete Research, Vol. 41, 1989, pp. 125-135.

88. Ji,G M, Kanstad, T, Bjøntegaard $\varnothing$ \& Sellevold E J: "Tensile and compressive creep deformations of hardening concrete containing mineral additives." Materials and Structures, Vol. 46, 2013, pp.1167-1182.

89. Bissonnette B \& Pigeon M: "Tensile creep at early ages of ordinary, silica fume and fiber reinforced concretes." Cement and Concrete Research, Vol. 25, 1995, pp.1075-1085.

90. Bissonnette B, Pigeon M \& Vaysburd A M:"Tensile creep of concrete: study of its sensitivity to basic parameters." ACI Materials Journal, Vol. 104, 2007, pp. 360.

91. Altoubat S A \& Lange D A: "Creep, shrinkage, and cracking of restrained concrete at early age." ACI Materials Journal, Vol. 98, 2001, pp. 323-331.

92. https://batman.trafikverket.se.

93. https://www.trafikverket.se/contentassets/359d9886c7504d349fe243739707a725/direktgju ten_slitbetong_den_enkla_och_kostnadseffektiva_metoden.pdf (downloaded December 2019) 